\title{
Selective Serotonin Reuptake Inhibitors May Improve the Efficacy of Hematopoietic Stem Cells Transplantation
}

\author{
Azadeh Anbarlou $^{1 \dagger}$, Mahshid Akhavan Rahnama ${ }^{2 \dagger}$, Amir Atashi ${ }^{1 *}$ and Masoud Soleimani ${ }^{1}$ \\ ${ }^{1}$ Department of Hematology, Faculty of Medical Sciences, Tarbiat Modares University, Tehran, Iran; ${ }^{2}$ Department of Hematology, Tabriz \\ University of Medical Sciences, Tabriz, Iran
}

\begin{abstract}
Hematopoietic stem cell (HSC) transplantation is the most effective therapeutic modality for certain malignant and non-malignant diseases. Although umbilical cord blood can be a source of HSCs, the harvest from a single cord is insufficient for transplantation. Protocols have been developed to overcome this problem, but in vivo expansion of transplanted HSCs would be most desirable. Serotonin is a monoamine neurotransmitter that can increase the ex vivo expansion of both HSCs and bone marrow stromal cells (BM$\mathrm{SCs}$ ). Selective serotonin reuptake inhibitors (SSRIs) increase the free serotonin concentration by binding to the serotonin transporter (SERT), thereby preventing reuptake by pre-synaptic cells. Studies have shown that SSRIs also have immunosuppressive effects. We hypothesized that the immunosuppressive effects of SSRIs may be due to the expansion of BMSCs, which can result in a decrease in the incidence of graft versus host disease (GVHD). Finally SSRIs may promote efficacy of transplantation by increasing the in vivo expansion of HSCs and decreasing GVHD incidence.
\end{abstract}

\section{Introduction}

Hematopoietic stem cells (HSCs) are stem cells that have the potential to develop into blood and immune cells. Especially, HSCs are defined by their ability to self-renew and produce cells able to differentiate into any blood cell type, although only small numbers divide and differentiate to a mature lineage. ${ }^{1,2}$ These properties render HSCs attractive for use in stem cell therapies. ${ }^{3}$

Transplantation of HSCs is the most effective modality for treating malignant and non-malignant diseases including leukemias and lymphomas, aplastic anemia, and hemoglobinopathies; genetic disorders such as lysosomal storage disease ${ }^{4,5}$; and immunodeficiencies such as human immunodeficiency virus (HIV)

Keywords: Selective serotonin reuptake inhibitor; Hematopoietic stem cell transplantation; Serotonin; 5-hydroxytryptamine; Stem cell expansion.

Abbreviations: AIDS, acquired immune deficiency syndrome; BMSCs, bone marrow stromal cells; EC, enterochromaffin; GVHD, graft versus host disease; HIV, human immunodeficiency virus; HSC, hematopoietic stem cell; SERT, serotonin reuptake transporter; SMCs, small-molecule compounds; SSRIs, selective serotonin reuptake inhibitors; TNF, tumor necrosis factor.

Received: 25 June 2015; Revised: 23 August 2015; Accepted: 8 September 2015

DOI: $10.14218 /$ JERP.2015.00001

$\dagger$ These authors contributed equally to this paper.

*Correspondence to: Amir Atashi, Department of Hematology, School of Medical Sciences, Tarbiat Modares University, P.O. Box: 14115-331, Tehran, Iran. Tel: +98218-2883579, Fax: +98-218-2884507, E-mail: atashia@modares.ac.ir infection and acquired immune deficiency syndrome (AIDS). ${ }^{6}$

The most common sources of HSCs for transplantation are bone marrow and mobilized peripheral blood. ${ }^{7}$ Major factors limiting the success of transplantation from these sources are graftversus-host disease $(\mathrm{GVHD})^{8,9}$ and engraftment failure. ${ }^{10}$ Since 1988, umbilical cord blood has increasingly become an alternative source of HSCs for transplantation, ${ }^{11}$ due to easy availability, lower risk of viral infection, and reduced GVHD. ${ }^{12}$ The number of HSCs in umbilical cord blood is low, but a population adequate for transplantation may be gained via ex vivo expansion. ${ }^{12}$ Most methods of ex vivo expansion, however, are not able to maintain stem cell properties and therefore are not appropriate for clinical application. Most desirable would be a new method that can induce the in vivo expansion of HSCs.

Small-molecule compounds (SMCs) are a relatively new tool for the expansion of HSCs, ${ }^{13}$ although these natural chemical products have been used in molecular biology and pharmacological treatments for many years. It has been shown that SMCs are able to modulate the signaling pathways of HSCs. ${ }^{14}$ One of these SMCs is serotonin (or 5-hydroxytryptamine, 5-HT), ${ }^{15}$ a monoamine neurotransmitter that is often produced in Enterochromaffin (EC) cells of the gut and brain, and stored in platelets and mast cells. ${ }^{16,17}$

Antidepressant drugs known as selective serotonin reuptake inhibitors (SSRIs) prevent the uptake of serotonin by SERT (serotonin reuptake transporter). This results in enhanced serotonin signaling. ${ }^{18,19}$ SSRIs are used to treat many diseases, including major depression and anxiety disorders (e.g., obsessive-compulsive disorder and panic disorder). Relative to other antidepressants, they cause fewer undesirable side effects. Paroxetine, citalopram, fluvoxamine, sertraline and fluoxetine are examples of SSRIs. ${ }^{20-22}$

SSRI treatments have been associated with changes in the proliferation, cytokine secretion, and viability of peripheral blood lymphocytes. ${ }^{19}$ Generally, SSRIs appear to inhibit the proliferation of T lymphocytes, with the exception of fluoxetine, whose stimulatory or inhibitory effects are dependent on the concentration of mitogen (concavalin A) and degree of lymphocyte activation in vitro. ${ }^{23,24}$

Serotonin has been identified as an important factor in the activation of T lymphocytes. Evidence-based conclusions are that serotonin receptors are not responsible for the mitogenic effects of serotonin on T lymphocytes, but rather SERT is responsible for these effects via the uptake of serotonin; internalization of serotonin through SERT leads to the proliferation of these cells. Therefore, the anti-proliferative effects of SSRIs can be explained by the inhibition of serotonin uptake. ${ }^{19}$

SSRIs are able to affect other parameters related to lymphocytes, such as cytokine secretion. Taler et al..$^{25}$ showed that, ex vivo, a higher concentration of the SSRIs paroxetine and sertraline 


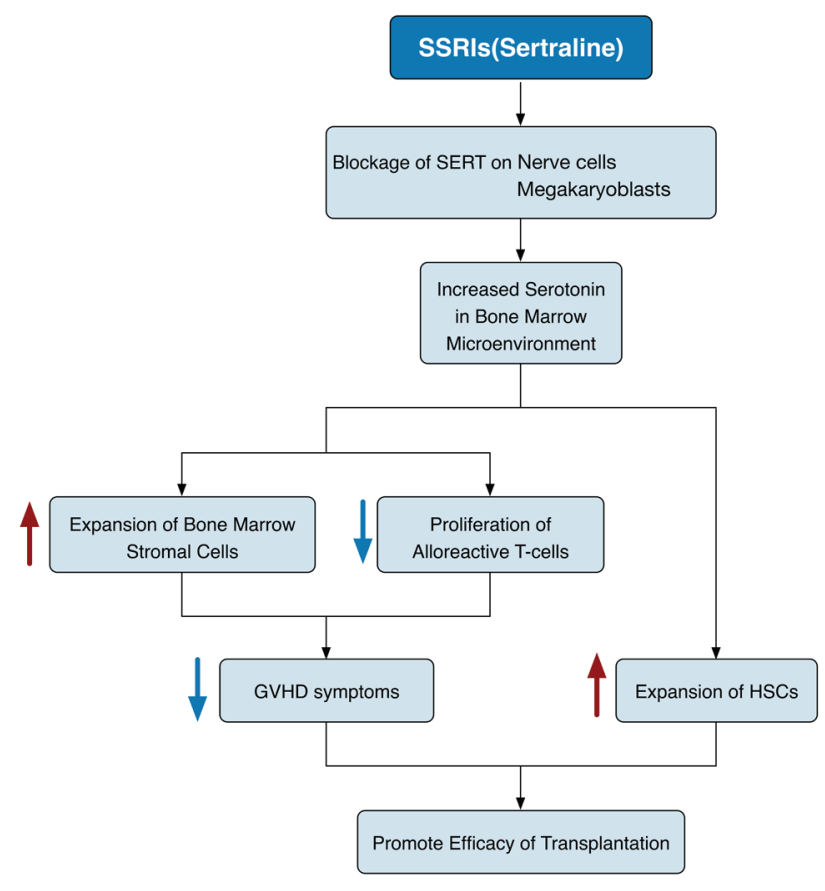

Fig. 1. Schematic diagram of the hypothetical mechanisms underlying SSRI promotion of HSC transplantation through in vivo expansion of HSCs and decrease in GVHD.

$(10 \mu \mathrm{M})$ was associated with inhibition of $\mathrm{T}$ cell proliferation and reduced secretion of tumor necrosis factor (TNF)- $\alpha$. These effects were related to the inhibition of gene expression by SSRIs, genes that are involved in the proliferation and inflammatory responses of lymphocytes. ${ }^{25-27}$

In addition, SSRIs induce apoptosis in lymphocytes. All SSRIs used in clinical practice (paroxetine, citalopram, fluvoxamine, sertraline and fluoxetine) had this apoptotic effect. Moreover, serotonin induces apoptosis in Burkitt's lymphoma cells. Therefore, the pro-apoptotic function of SSRIs may be related to increased extracellular serotonin. ${ }^{19}$

The above discussion highlights that most researchers have reported immunosuppressive effects associated with SSRIs, effects that include lymphocyte proliferation and secretion of pro-inflammatory cytokines. Fluoxetine was shown to exert both immunosuppressive and immunomodulatory effects depending on the used concentration, but other SSRIs such as sertraline and paroxetine were associated with only immunosuppressive effects.

Fluoxetine $(20 \mathrm{mg} / \mathrm{kg})$ was able to reduce the clinical symptoms of acute GVHD after HSC transplantation. In the peripheral blood of mice treated with fluoxetine, a low percentage of alloreactive T-cells were detected. This indicates that fluoxetine can reduce the proliferation of alloreactive T-cells, increase the apoptosis of these cells, or both. In addition, fluoxetine increased the survival of mice by at least 6 months post-transplantation. ${ }^{28}$

\section{Hypothesis}

By increasing the amounts of serotonin in bone marrow, SSRIs may improve the efficacy of HSC transplantation (Fig. 1). Most studies concerning SSRIs have focused on the effects of sertraline and fluoxetine. Because the effects of fluoxetine on lymphocytes are variable under different conditions, we suggest sertraline, as its effect is solely immunosuppressive. The routine starting dosage of sertraline as an antidepressant is $50 \mathrm{mg} / \mathrm{day}$, and the maximum is $200 \mathrm{mg} /$ day, ${ }^{29,30}$ but higher doses are probably required for immunosuppression. ${ }^{19}$ The normal concentration of serotonin in plasma is $0.62 \pm 0.11 \mu \mathrm{g} / \mathrm{L} .{ }^{31}$ Future studies must focus on the dosage of sertraline that will generate the optimum concentration of plasma serotonin for in vivo expansion of HSCs.

\section{Evaluation of hypothesis}

In addition to bone and hematopoietic cells, nerve cells are also within the microenvironment of the bone marrow, and interactions among these cells regulate the fate of stem cells in vivo. ${ }^{15}$ The following evidence suggests that these complex interactions may be through the serotonin neurotransmitter. Firstly, serotonin can stimulate megakaryopoiesis via the $5-\mathrm{HT}_{2}$ receptor. ${ }^{32}$ In the early stages of megakaryocytopoiesis, serotonin regulates proliferation and survival of megakaryoblasts through its anti-apoptotic effects. ${ }^{32,33}$ SERT in also found on platelets, enabling storage of serotonin in the blood. ${ }^{34}$ About $90 \%$ of the serotonin in blood is stored in dense granules of platelets. Since the expression of SERT on megakaryocytic lineage has been demonstrated, ${ }^{34}$ we can hypothesize that SERT is also expressed in megakaryoblasts. Yang et al. ${ }^{32}$ observed reduced levels of caspase- 3 in megakaryoblastic cells (M-07e) treated with serotonin. The anti-apoptotic effects of serotonin are similar to that of thrombopoietin, a known cytokine in hematopoiesis and megakaryocytopoiesis. ${ }^{32}$ Kirouac et al. ${ }^{15}$ also showed that serotonin is produced endogenously by hematopoietic cells. Thus, perhaps megakaryocytes are involved in this process. As we know, HSC expansion is associated with the development of megakaryocytes, ${ }^{15}$ and serotonin secreted from megakaryocytes promotes stem cell self-renewal. ${ }^{15,35}$

That the fate of stem cells in vivo may be ultimately regulated through the serotonin neurotransmitter is further supported by reports that serotonin was associated with increased ex vivo expansion of $\mathrm{CD}_{34} 4^{+} \mathrm{HSCs}$ in mice ${ }^{32,36}$; Yang et al. ${ }^{32}$ reported that serotonin expanded CD $34^{+}$cells by $12.2 \pm 1.79$-fold ex vivo. The expansion not only led to cell proliferation but also to increased levels of early progenitors and the density of multilineage colony-forming units. Serotonin enhanced the proliferation of HSCs in bone marrow via activation of the $5-\mathrm{HT}_{2}$ receptor. ${ }^{36}$ In parallel with previous studies, Spiegel et al. ${ }^{37}$ also showed that serotonin increased HSC proliferation and engraftment in vivo. Moreover, PNU 22394 (a 5-HT 2 agonist) led to reduced levels of erythroid precursors in bone marrow through $5-\mathrm{HT}_{2 \mathrm{~A}}$ and $5-\mathrm{HT}_{2 \mathrm{~B}}$ receptors. This proliferative effect on erythroid precursors is similar to that exerted by serotonin. ${ }^{33}$

Finally, further evidence of the role of serotonin neurotransmitters is that serotonin was found to stimulate the formation of bone marrow stromal cells (BMSCs) from colony-forming unit fibroblasts. ${ }^{32}$ BMSCs have immunoregulatory properties and they can affect the development, maturation, and function of immune effector cells such as alloreactive T-cell responses. ${ }^{17}$

\section{Discussion and conclusions}

There are several sources of serotonin in the body. Among them, infiltrating neurons in bone marrow and other tissues may secrete serotonin and other ligands that can affect the expansion of HSCs. ${ }^{35}$ We consider that human consumption of SSRIs after infusion of $\mathrm{CD} 34^{+}$HSCs may be beneficial from multiple aspects. 
These drugs can increase the accessibility of serotonin to HSCs by several pathways; one of which is blockage of SERT in the nerve terminals of infiltrating neurons to the bone marrow microenvironment and megakaryoblast. Reuptake of serotonin is prevented by inhibition of SERT, and therefore serotonin concentrations increase in the microenvironment of the bone marrow.

There is also some evidence that megakaryoblasts are able to synthesize serotonin. ${ }^{15,35}$ Our hypothesis is that serotonin cannot enter megakaryoblasts because of SERT blockage. It seems likely that this results in elevated levels of serotonin in the bone marrow, by increasing serotonin synthesis via megakaryoblasts (compensating for serotonin deficiency). Finally, this will lead to the expansion of $\mathrm{CD} 34^{+} \mathrm{HSCs}$ and early progenitors, in vivo.

Serotonin also can increase expansion of BMSCs. ${ }^{32}$ These cells have immunoregulatory properties and can decrease GVHD symptoms. To take advantage of this property, co-infusion of mesenchymal stem cells with $\mathrm{CD} 34^{+} \mathrm{HSCs}$ was recently reported as a novel protocol in HSC transplantation. ${ }^{38-40}$

On the other hand, some studies have shown that SSRIs have immunosuppressive effects, and we hypothesized that this may be due to increased serotonin in the bone marrow microenvironment that leads to an increase in the expansion of BMSCs. Therefore, the observed immunosuppressive effects may be the result of expansion of BMSCs that lead to a decrease in GVHD symptoms. Hirota et al. ${ }^{17}$ demonstrated that serotonin $(10 \mu \mathrm{M})$ was able induce rat BMSC differentiation into smooth muscle-like cells in vitro. Moreover, SSRIs (except citalopram) have been shown to have negative effects on human osteoclasts and osteoblasts. ${ }^{41}$ Thus the possible side effects of SSRIs should be considered.

Altogether we conclude that SSRIs may promote the efficacy of HSC transplantation by increasing the in vivo expansion of HSCs and decreasing the incidence of GVHD.

\section{Acknowledgements}

The present work is supported by Tarbiat Modares University, Tehran, Iran.

\section{Conflict of interest}

None.

\section{Author contributions}

Writing the manuscript (AA, MAR, AA, MS).

\section{References}

[1] Till J, McCullough E. A direct measurement of the radiation sensitivity of normal mouse bone marrow cells. Radiat Res 1961;14:213-22. doi: 10.2307/3570892.

[2] Marshak DR, Gottlieb D, Kiger AA, Fuller MT, Kunath T, Hogan B, et al. Stem cell biology. Marshak DR, Gardner RL, Gottlieb D, eds. New York: Cold Spring Harbor Laboratory Press, 2001.

[3] Regenerative Medicine. In: Stem Cell Information. Bethesda, MD: National Institutes of Health, U.S. Department of Health and Human Services, 2011.

[4] Lund TC. Hematopoietic stem cell transplant for lysosomal storage diseases. Pediatr Endocrinol Rev PER 2013;11:91-8.

[5] Gratwohl A, Baldomero H, Aljurf M, Pasquini MC, Bouzas LF, Yoshimi A, et al. Hematopoietic stem cell transplantation: a global perspective. JAMA 2010;303(16):1617-24. doi: 10.1001/jama.2010.491.

[6] Snowden JA, Saccardi R, Allez M, Ardizzone S, Arnold R, Cervera R, et al.
Haematopoietic SCT in severe autoimmune diseases: updated guidelines of the European Group for Blood and Marrow Transplantation. Bone Marrow Transplant 2012;47(6):770-90. doi: 10.1038/bmt.2011.185.

[7] Nishino T, Osawa M, Iwama A. New approaches to expand hematopoietic stem and progenitor cells. Expert Opin Biol Ther 2012;12(6):743-56. doi: 10.1517/14712598.2012.681372.

[8] Ferrara JLM, Levine JE, Reddy P, Holler E. Graft-versus-host disease. Lancet 2009;373(9674):1550-61. doi: 10.1016/S0140-6736(09)60237-3.

[9] Paczesny S, Hanauer D, Sun Y, Reddy P. New perspectives on the biology of acute GVHD. Bone Marrow Transplant 2010;45(1):1-11. doi: 10.1038 bmt.2009.328.

[10] Gonçalves TL, Benvegnú DM, Bonfanti G. Specific factors influence the success of autologous and allogeneic hematopoietic stem cell transplantation. Oxid Med Cell Longev 2009;2(2):82-7. doi: 10.4161/oxim.2.2.8355.

[11] Tse W, Laughlin MJ. Umbilical cord blood transplantation: a new alternative option. ASH Educ Progr B 2005;2005(1):377-83.

[12] Schuster JA, Stupnikov MR, Ma G, Liao W, Lai R, Ma Y, et al. Expansion of hematopoietic stem cells for transplantation: current perspectives. Exp Hematol Oncol 2012;1(1):12. doi: 10.1186/2162-3619-1-12.

[13] Nakajima-Takagi Y, Osawa M, Iwama A. Manipulation of hematopoietic stem cells for regenerative medicine. Anat Rec 2014;297(1):111-20. doi: 10.1002/ ar.22804.

[14] Bouchez LC, Boitano AE, de Lichtervelde L, Romeo R, Cooke MP, Schultz PG. Small-Molecule Regulators of Human Stem Cell Self-Renewal. ChemBioChem 2011;12(6):854-7. doi: 10.1002/cbic.201000734.

[15] Kirouac DC, Ito C, Csaszar E, Roch A, Yu M, Sykes EA, et al. Dynamic interaction networks in a hierarchically organized tissue. Mol Syst Biol 2010;6(1):417.

[16] Mössner R, Lesch K-P. Role of serotonin in the immune system and in neuroimmune interactions. Brain Behav Immun 1998;12(4):249-71.

[17] Hirota N, McCuaig S, O'Sullivan MJ, Martin JG. Serotonin augments smooth muscle differentiation of bone marrow stromal cells. Stem Cell Res 2014;12(3):599-609. doi: 10.1016/j.scr.2014.02.003.

[18] Chen X, Margolis KJ, Gershon MD, Schwartz GJ, Sze JY. Reduced serotonin reuptake transporter (SERT) function causes insulin resistance and hepatic steatosis independent of food intake. PLoS One 2012;7(3):e32511. doi: 10.1371/ journal.pone.0032511.

[19] Gobin V, Van Steendam K, Denys D, Deforce D. Selective serotonin reuptake inhibitors as a novel class of immunosuppressants. Int Immunopharmacol 2014;20(1):148-56. doi: 10.1016/j.intimp.2014.02.030.

[20] Hiemke C, Härtter S. Pharmacokinetics of selective serotonin reuptake inhibitors. Pharmacol Ther 2000;85(1):11-28. doi: 10.1016/S0163-7258(99)00048-0.

[21] Serretti A, Artioli P. The pharmacogenomics of selective serotonin reuptake in hibitors. Pharmacogenomics J 2004;4(4):233-44. doi: 10.1038/sj.tpj.6500250.

[22] Thomas KLH, Ellingrod VL. Pharmacogenetics of selective serotonin reuptake inhibitors and associated adverse drug reactions. Pharmacother J Hum Pharmacol Drug Ther 2009;29(7):822-31. doi: 10.1592/phco.29.7.822.

[23] Edgar VA, Genaro AM, Cremaschi G, Sterin-Borda L. Fluoxetine action on murine T-lymphocyte proliferation: participation of PKC activation and calcium mobilisation. Cell Signal 1998;10(10):721-6. doi: 10.1016/S0898 6568(98)00016-3.

[24] Edgar VA, Sterin-Borda L, Cremaschi GA, Genaro AM. Role of protein kinase $\mathrm{C}$ and cAMP in fluoxetine effects on human T-cell proliferation. Eur J Pharmacol 1999;372(1):65-73. doi: 10.1016/S0014-2999(99)00142-9.

[25] Taler M, Gil-Ad I, Lomnitski L, Korov I, Baharav E, Bar M, et al. Immunomodulatory effect of selective serotonin reuptake inhibitors (SSRIs) on human T lymphocyte function and gene expression. Eur Neuropsychopharmacol 2007;17(12):774-80. doi: 10.1016/j.euroneuro.2007.03.010.

[26] Frick LR, Palumbo ML, Zappia MP, Brocco MA, Cremaschi GA, Genaro AM. Inhibitory effect of fluoxetine on lymphoma growth through the modulation of antitumor T-cell response by serotonin-dependent and independent mechanisms. Biochem Pharmacol 2008;75(9):1817-26. doi: 10.1016/j.bcp.2008.01.015.

[27] Diamond M, Kelly JP, Connor TJ. Antidepressants suppress production of the Th 1 cytokine interferon- $\gamma$, independent of monoamine transporter blockade. Eur Neuropsychopharmacol 2006;16(7):481-90. doi: 10.1016/j.euroneuro.2005.11.011.

[28] Gobin V, Van Steendam K, Fevery S, Tilleman K, Billiau AD, Denys D, et al. Fluoxetine reduces murine graft-versus-host disease by induction of T cell immunosuppression. J Neuroimmune Pharmacol 2013;8(4):934 43. doi: 10.1007 s11481-013-9463-7.

[29] Löwe B, Schenkel I, Bair MJ, Göbel C. Efficacy, predictors of therapy response, and safety of sertraline in routine clinical practice: prospective, open-label, noninterventional postmarketing surveillance study in 1878 patients. J Affect Disord 2005;87(2):271-9. doi: 10.1016/j.jad.2005.05.005.

[30] Do Rosario-Campos MC, Leckman JF, Mercadante MT, Shavitt RG, Prado H da S, Sada P, et al. Adults with early-onset obsessive-compulsive disorder. Am J Psychiatry 2001;158(11):1899-903. doi: 10.1176/appi.ajp.158.11.1899.

[31] Lee MS, Cheng FC, Yeh HZ, Liou TY, Liu JH. Determination of plasma serotonin and 5-hydroxyindoleacetic acid in healthy subjects and cancer patients. Clin Chem 2000;46(3):422-3.

[32] Yang M, Li K, Ng PC, Chuen CKY, Lau TK, Cheng YS, et al. Promoting effects 
of serotonin on hematopoiesis: ex vivo expansion of cord blood CD34 ${ }^{+}$stem/ progenitor cells, proliferation of bone marrow stromal cells, and antiapoptosis. Stem Cells 2007;25(7):1800-6. doi: 10.1634/stemcells.2007-0048.

[33] Launay JM, Hervé P, Callebert J, Mallat Z, Collet C, Doly S, et al. Serotonin 5 -HT2B receptors are required for bone-marrow contribution to pulmonary arterial hypertension. Blood 2012;119(7):1772-80. doi: 10.1182/ blood-2011-06-358374.

[34] Leon-Ponte M, Ahern GP, O'Connell PJ. Serotonin provides an accessory signal to enhance T-cell activation by signaling through the 5-HT7 receptor. Blood 2007;109(8):3139-46. doi: 10.1182/blood-2006-10-052787.

[35] Gaudet S. Connecting cell fate decision networks in hematopoeisis from the outside in. Mol Syst Biol 2010;6(1):418.

[36] Park KE, Pepine CJ. Pathophysiologic mechanisms linking impaired cardiovascular health and neurologic dysfunction: the year in review. Cleve Clin J Med 2010;77(Suppl 3):S40-5.

[37] Spiegel A, Kalinkovich A, Shivtiel S, Kollet O, Lapidot T. Stem cell regulation via dynamic interactions of the nervous and immune systems with the microenvironment. Cell Stem Cell 2008;3(5):484-92. doi: 10.1016/j.stem.2008.10.006

[38] Meuleman N, Tondreau T, Ahmad I, Kwan J, Crokaert F, Delforge A, et al. Infusion of mesenchymal stromal cells can aid hematopoietic recovery following allogeneic hematopoietic stem cell myeloablative transplant: a pilot study. Stem Cells Dev 2009;18(9):1247-52. doi: 10.1089/scd.2009.0029.

[39] Le Blanc K, Samuelsson H, Gustafsson B, Remberger M, Sundberg B, Arvidson $\mathrm{J}$, et al. Transplantation of mesenchymal stem cells to enhance engraftment of hematopoietic stem cells. Leukemia 2007;21(8):1733-8. doi: 10.1038/ sj.leu.2404777.

[40] Giordano A, Galderisi U, Marino IR. From the laboratory bench to the patient's bedside: an update on clinical trials with mesenchymal stem cells. J Cell Physiol 2007;211(1):27-35. doi: 10.1002/jcp.20959.

[41] Tsapakis EM, Gamie Z, Tran GT, Adshead S, Lampard A, Mantalaris A, et al. The adverse skeletal effects of selective serotonin reuptake inhibitors. Eur psychiatry 2012;27(3):156-69. doi: 10.1016/j.eurpsy.2010.10.006. 